\title{
Fracture banding in caving mines
}

\author{
by D. Cumming-Potvin*, J. Wesseloo*, S.W. Jacobsz ${ }^{\dagger}$, and \\ E. Kearsley ${ }^{\dagger}$
}

\section{Synopsis}

The Duplancic model of caving is widely accepted in industry and is the framework within which most monitoring and numerical modelling results in caving mines are interpreted. As a result, the damage profile ahead of the cave back is often interpreted as continuously decreasing damage with increasing distance ahead of the cave back. Physical modelling of the caving process performed in a centrifuge did not support this expected behaviour, but instead suggested a discontinuous damage profile ahead of the cave caused by fracture banding. Some support is found in the literature to suggest that the behaviour observed in the models may also be present in the field. This notion is further supported by banding behaviour observed from microseismic monitoring at two block cave mines. Combining the information from the physical models, field observations referred to in the literature, and the microseismic analyses, it is concluded that the Duplancic model needs to be extended to include the phenomenon of fracture banding. It is also reasonable to expect that fracture banding may play a more important role in the caving process than has previously been recognized.

Keywords

block caving, caving mechanics, fracture banding, extensional fracturing, centrifuge, physical modelling.

\section{Introduction}

The Duplancic model of caving (Duplancic, 2001) is widely accepted in industry and is the framework within which most monitoring and numerical modelling results in caving mines are interpreted. The Duplancic model was created based primarily on simple microseismic analysis and linear elastic numerical modelling of one case study. At the time, it provided a much-needed interpretation framework and, as a result, has been applied to numerous mines. The model is generally interpreted as indicating that the damage ahead of the cave back in block caving mines continuously decreases with increasing distance from the cave back. From basic seismic analysis and with the assumption that slip along preexisting discontinuities will take place preferentially to intact rock failure, Duplancic found that the most likely failure mechanism in the cave crown was slip along pre-existing discontinuities. As such, the model downplays the role of intact rock failure, including extensional failure. Extensional fracturing occurs parallel to the major principal stress and perpendicular to the maximum extensional strain. This may occur under a compressive macro-stress regime (Stacey, 1981).

Physical modelling of cave development in a centrifuge was carried out, and the results of the physical modelling did not correspond with the expectation of the Duplancic model. The main mechanism of cave propagation observed in the physical models was via a series of extensional fractures parallel to the cave back.

This discrepancy between the Duplancic model and the physical model raises the question whether the governing mechanism evident in the physical models is also present in the field, and whether the Duplancic conceptual model for caving mechanics should be reviewed.

A literature review revealed that several observations that were made in the past support the existence in the field of the mechanism evident in the physical models, although it seems that the importance and the full implication of these observations were not appreciated by the respective authors.

In addition to the physical models and literature review, an investigation was performed in order to establish whether any banding formation can be supported by the interpretation of microseismic monitoring data in modern block caving mines. Analysis of microseismicity was conducted at two large copper-gold porphyry block cave operations. The results of the analysis indicated that the mechanism seen in the physical model may have occurred at both mines.

This paper discusses the Duplancic model and presents an overview of the results from the physical modelling, literature review, and microseismic event monitoring.

\footnotetext{
* Australian Centre for Geomechanics, University of Western Australia, Australia.

+ University of Pretoria, Pretoria, South Africa.

(c) The Southern African Institute of Mining and Metallurgy, 2016. ISSN 2225-6253. Paper received Apr. 2016; revised paper received Jun. 2016.
} 


\section{Fracture banding in caving mines}

\section{The Duplancic model}

The Duplancic conceptual model of caving (Duplancic and Brady, 1999; Duplancic, 2001) is illustrated in Figure 1. The model is composed of five caving zones, which together describe the caving profile from the initiation of selfpropagation until the cave breakthrough. These zones were developed based on research using data from Northparkes E26 Lift 1 block cave mine. The five zones are defined by Duplancic (2001) as:

(1) Caved zone-The region of displaced (caved material) that has fallen from the cave and provides support to the walls

(2) Air gap-A gap between the caved zone and the cave back

(3) Zone of loosening-A zone of fractured rock that provides no support to the overlying rock mass and where disintegration of the rock mass occurs. Loss of confinement controls failure in this region. The failure in this region is aseismic

(4) Seismogenic zone-An active stress front where seismic failure of the rock mass occurs. It was determined that the most likely mode of failure in this region is slip along pre-existing discontinuities

(5) Pseudo-continuous domain-The volume of rock ahead of the seismogenic zone. Only elastic deformation occurs in this region.

This conceptual caving model has been widely accepted by the mining industry and is the framework within which most monitoring results are interpreted (e.g. Brown, 2007; Pfitzner et al., 2010). However, the model does not appear to have been rigorously and independently verified.

This conceptual model implies that the rock ahead of the cave back progresses through each of these zones consecutively as the cave propagates. Hence, the damage ahead of the cave back at any point in time decreases continuously with increasing distance from the back (i.e., the damage profile is continuous in space). This is how the model had been interpreted in the industry, as evidenced by Brown (2007) who stated that 'the boundaries between these regions are diffuse rather than sharp' and 'the rock mass undergoes a gradual reduction in strength from its in situ state to its caved state'.

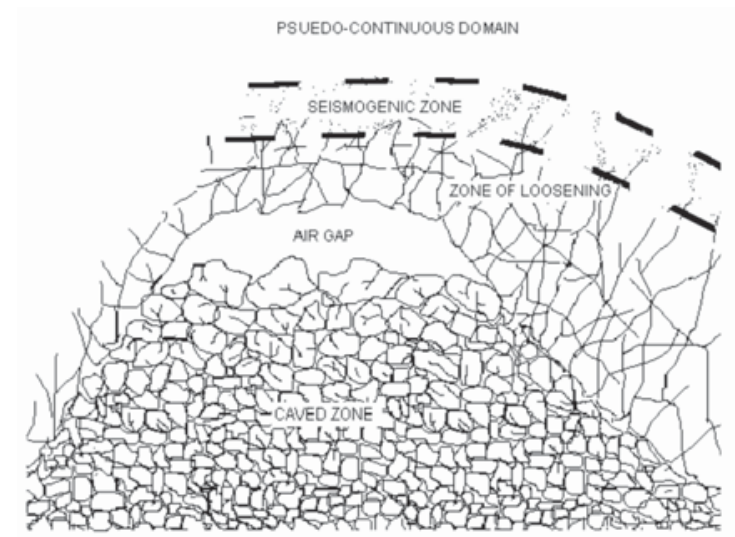

Figure 1-Conceptual model of caving (Duplancic, 2001)
In assuming that slip along pre-existing discontinuities will occur preferentially to intact rock failure (including through an extensional mechanism), Duplancic also emphasizes the hypothesis that failure in the cave back is due to the former and downplays the role of the latter in the caving process.

It is important to note that the Duplancic model of caving is based on one case study, Northparkes E26 Lift 1.

Duplancic did not have any instrumentation in the cave back, nor access to any areas of the cave back for visual observation. He relied on the interpretation of linear elastic numerical modelling and simple analysis of seismicity (focal plane analysis, event locations on sections, and $\mathrm{S}$ to $\mathrm{P}$ wave energy ratio). While the analyses conducted were relatively simple compared with current capabilities, it should be noted that Northparkes was one of the first mines to use a microseismic monitoring system to better understand cave mechanics.

Despite being based on a single case study, the Duplancic model has been applied to monitoring results from many other caving mines (Hudyma and Potvin, 2008; Pfitzner et al., 2010; Westman et. al., 2012, Abolfazlzadeh, 2013). However, the universality of the conclusions that Duplancic draws are called into question by the results of the physical modelling described in this paper.

\section{Centrifuge modelling}

\section{Overview}

Cumming-Potvin et al. (2016) developed a series of physical models with the aim of creating representative examples of cave propagation. Physical testing was performed in the geotechnical centrifuge facility at the University of Pretoria (Jacobsz et. al., 2014). Samples for the caving material were created using weakly cemented sand and fly ash mixtures and a network of fully closed (healed) joints was cut into the sample while it was curing. The fly ash was included in the sample mix in order to increase the brittleness of the material to better mimic the stress-strain behaviour of rock. To date, no specific tests of brittleness have been conducted and further research would be needed to determine the effect of brittleness on the results of the tests.

Horizontal stress was applied through water-filled bladders on the sides of the samples. The samples were tested at 80 times the acceleration due to earth's gravity, and the cave mining undercut was simulated by the retraction of five hydraulic pistons. The tests were essentially twodimensional, allowing visual observations of the caving process to be made using the digital single-lens reflex (DSLR) camera on board the centrifuge.

The two-dimensionality of the test, together with the restraints in front of and behind the samples, creates a situation that is close to plane strain. The test was inherently limited in its ability to simulate the stresses and expansion of the cave in the third dimension; however, the twodimensionality allows visual observation of the caving mechanisms and cave growth.

During the design and execution of the physical modelling programme, the expectation was that the caving in the physical model would resemble (and independently verify) the Duplancic conceptual model. However, the results 


\section{Fracture banding in caving mines}

did not correspond with this expected behaviour. Instead, a series of fractures developed parallel to and ahead of the cave front and the cave periphery. These fractures were judged to be extensional, due to the direction of movement and lack of damage to the asperities along the fractures. The cave progressed as a series of 'jumps' to successive parallel fractures. This created a discontinuous damage profile ahead of the cave back, contrasting with the common interpretation of a continuous damage profile in the Duplancic model.

For convenience, the phenomenon of parallel fracturing ahead of the cave back is referred to herein as fracture banding. Although the evidence is not definitive, it suggests that these fractures form in extension.

\section{Some results of physical modelling}

The test programme was conducted using five samples. Fracture banding resulted in all of the tests.

Photographs at the ends of the tests on samples 1-4 are shown in Figures 2-5, respectively. Figure 6 is a photograph of the test on sample 5 at the stage when the last undercut piston was extracted. The upward progression of the cave through the fracture banding process is demonstrated in Figure 7 at several stages in the test on sample 3. Two images are shown in each of Figures 2-5; the one, labelled A, without any markings and the other, labelled B, with the markings delineating fractures as described below.

In Figures 2-6, the parallel fractures in each test are highlighted by solid red lines. In Figures 3 and 5 (tests 2 and 4), large pre-existing discontinuities (analogous to faults) gave rise to large shear movements, as shown in blue lines.
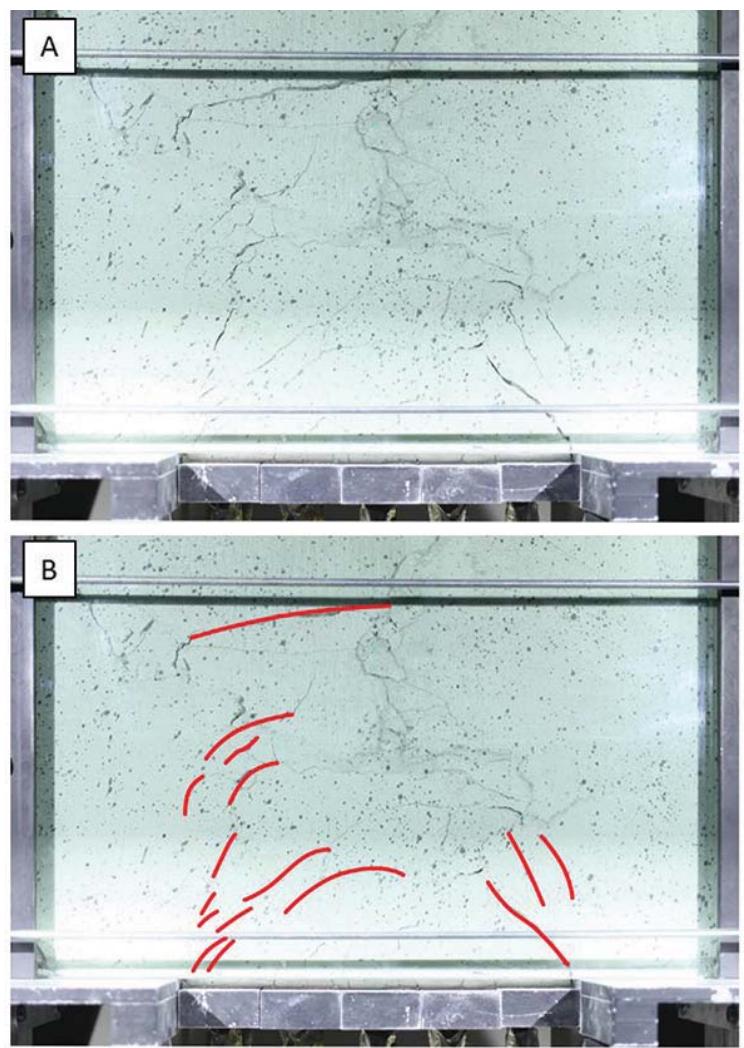

Figure 2-Parallel fractures ahead of the cave front and on the cave periphery (test 1)
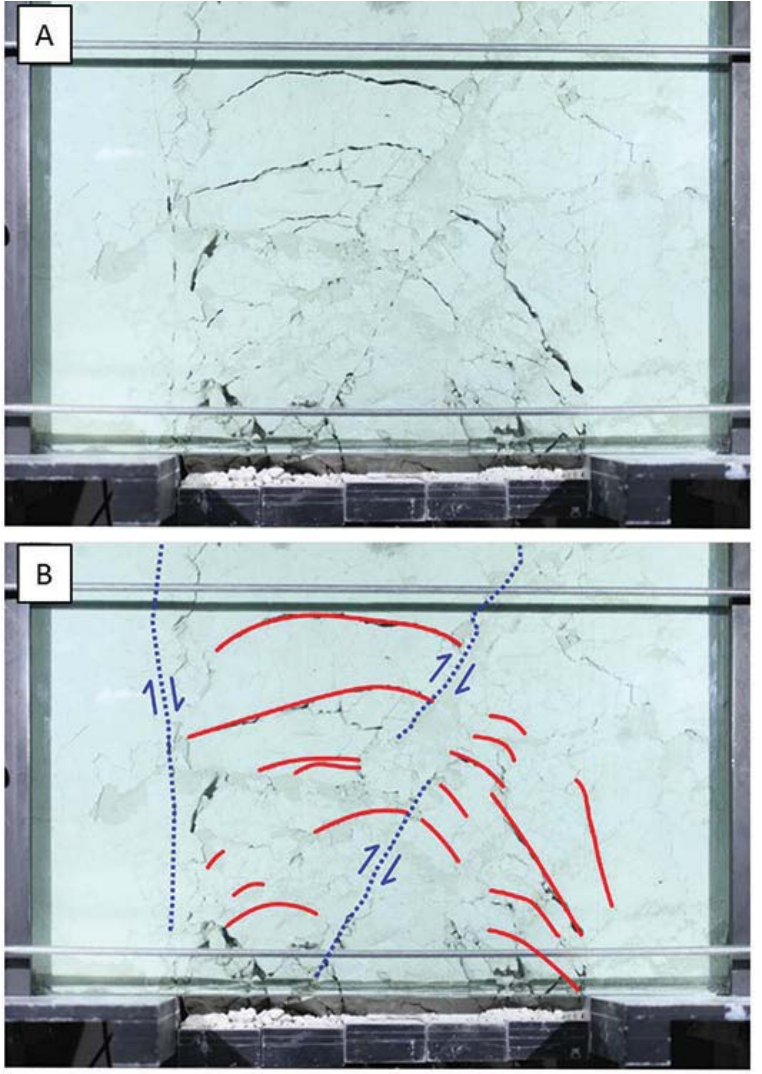

Figure 3-Parallel fractures ahead of the cave front and on the cave periphery, together with major shear discontinuities (test 2)
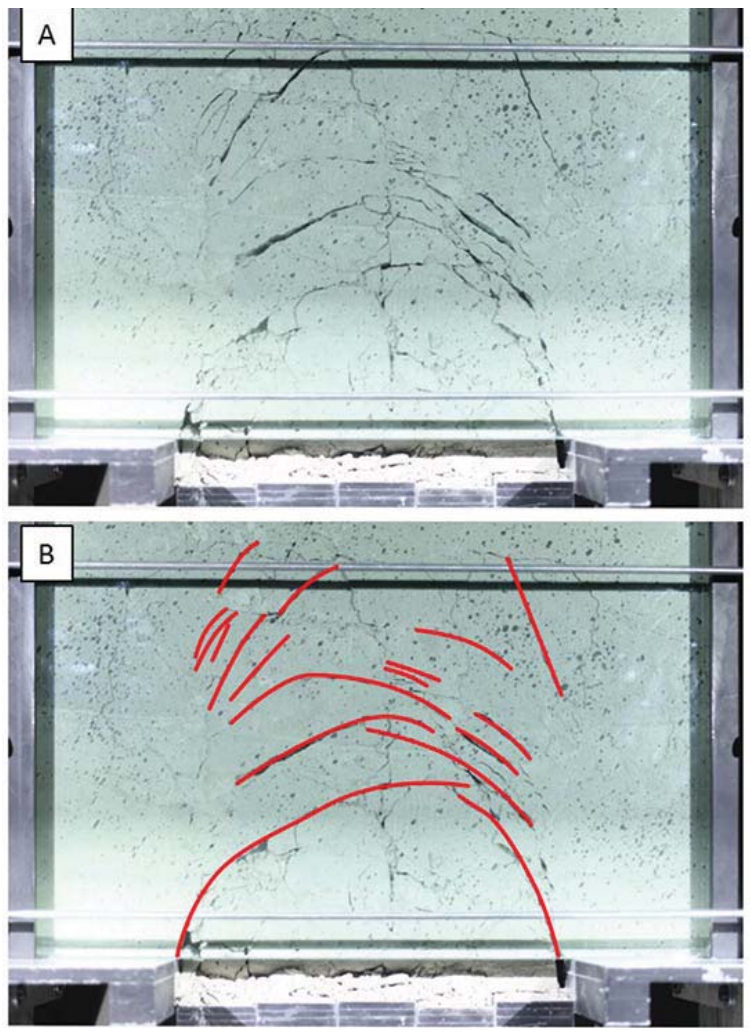

Figure 4-Parallel fractures ahead of the cave front and on the cave periphery (test 3 ) 


\section{Fracture banding in caving mines}

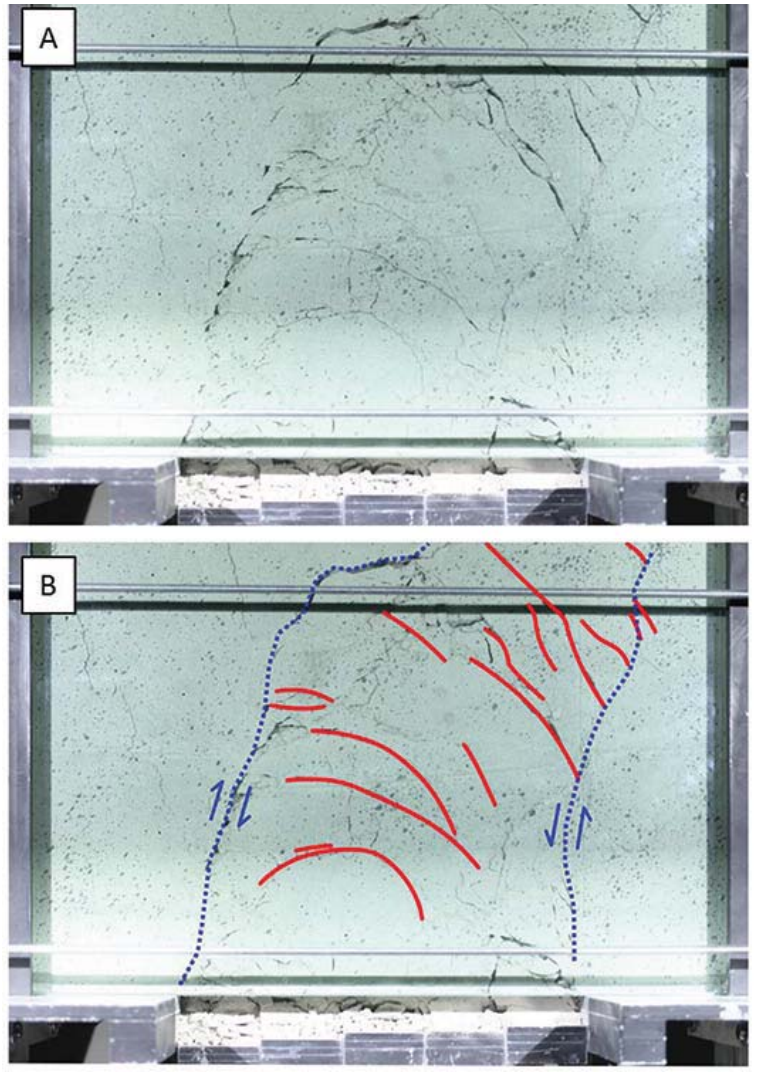

Figure 5-Parallel fractures ahead of the cave front and on the cave periphery, together with major shear discontinuities (test 4)

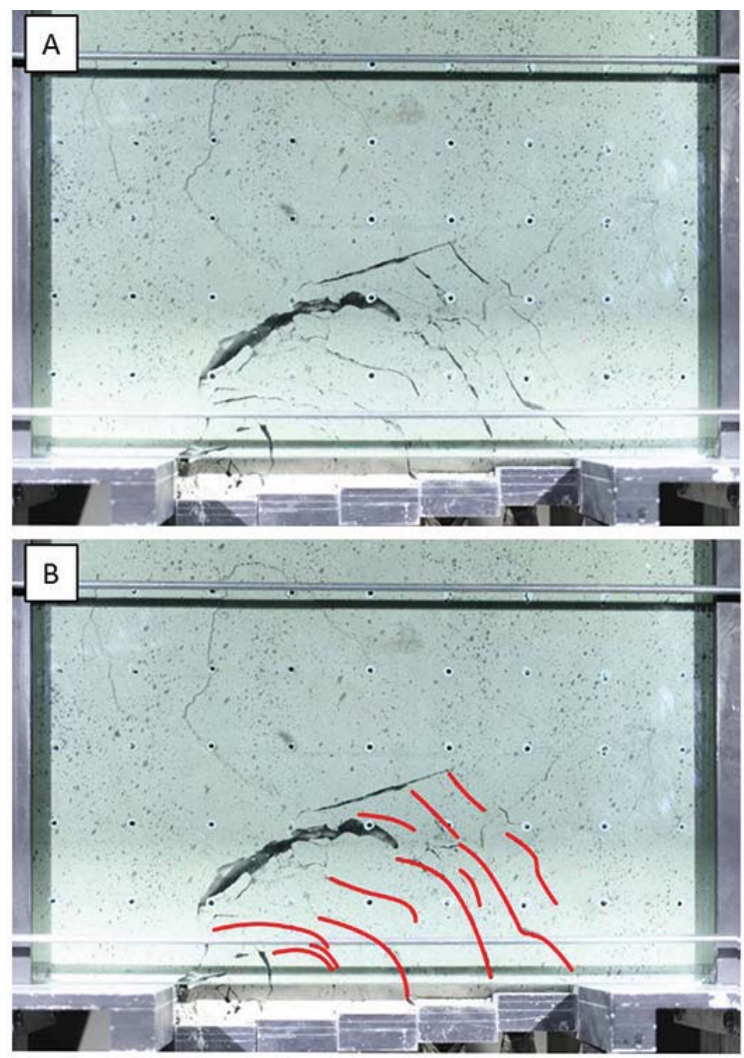

Figure 6-Parallel fractures ahead of the cave front and on the cave periphery (test 5)

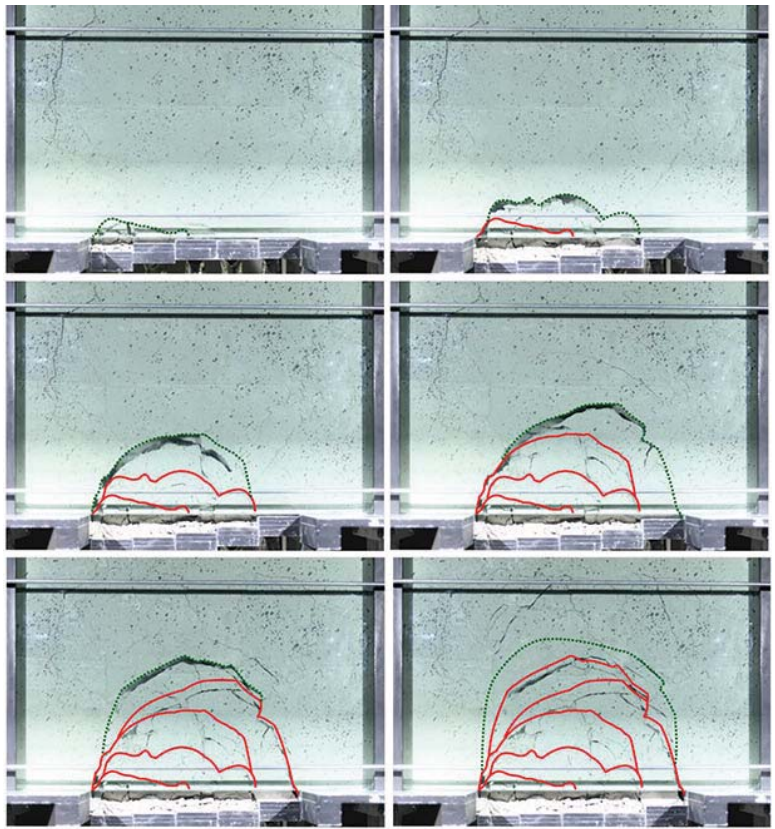

Figure 7-Cave progression (test 3)

In Figure 7 , the current cave outlines at the various stages are highlighted with dashed green lines while the previous cave outlines are highlighted with solid red lines.

It is worth noting that although the spacing of the fractures was not consistent between tests, it was relatively consistent within each test, indicating that the spacing might be a function of the material properties and stress state. As some of the fractures terminated at the edge of the pistons, this may create the impression that the fracture banding is an artificial by-product of the fact that the 'undercutting' was performed with comparatively wide pistons. A careful investigation of the data, however, does not support such an interpretation. While the retraction of the pistons may have affected the termination point of the fractures, there were many parallel fractures that did not coincide with the edge of the pistons (shown in dashed orange lines in Figure 8), confirming that the pistons had little influence on the initiation and propagation of the fractures in the early stages. In addition, fracture banding in Figure 3 formed between the two 'faults', some distance away from the 'undercut', and in an area and during a time period when the undercut method could not have influenced the mode of cave propagation.

\section{Literature on cave mechanics}

The discrepancy between the expected Duplancic behaviour and the observed fracture banding behaviour prompted a thorough literature review on caving mechanics. The review included three focus areas, namely literature on other physical models, observations from caving mines, and numerical models.

\section{Physical modelling in the literature}

Most physical modelling experiments in caving have focused on draw control, and there have been very few physical 


\section{Fracture banding in caving mines}

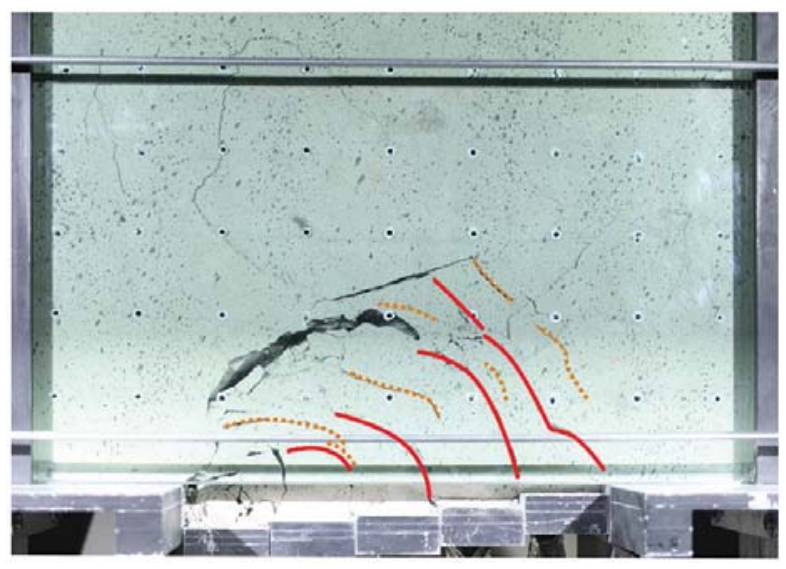

Figure 8-Fractures lining up with edges of pistons (solid red lines) and those that do not (dashed orange lines)

models that investigated the caving process itself. McNearny and Abel (1993) created a two-dimensional model of caving using layers of bricks, primarily to investigate the effect of drawpoint spacing. Duplancic (2001) points out the limitations of the model, stating that 'the regular jointing formed in the model is not representative of the random nature of a real jointing pattern' and 'the lack of horizontal confining stresses limits its contribution to the understanding of caving mechanics'. Although the test had significant flaws, limiting its ability to increase the understanding of caving mechanics, it is interesting to note that the bricks separated from each other parallel to and ahead of the caving void surface; this was interpreted as representing extensional fractures similar to the pattern observed by Panek (1981) at San Manuel Mine. These results, in principle, support the phenomenon of fracture banding as an important mechanism in cave propagation.

Nishida et al. (1986) created a base friction model that included horizontal stress applied using hydraulic jacks in order to study subsidence from cave-ins in Japan. The formation of these sinkholes is not an equivalent situation to that of a block caving mine, representing low-strength material at shallow depths and a single jointing pattern. Despite these differences, there are still some similarities between the two cases. Figure 9 shows a typical test of the cave-in using the base friction model. The fracture pattern reveals a discontinuous damage profile, with a series of parallel fractures ahead of the cave surface (i.e. fracture banding). These fractures do not coincide with the boundaries between the layers in the sample and thus are not a failure mechanism controlled by the layered nature of the model. The authors were primarily focused on the final subsidence profile, and as such presented no discussion on the failure mechanism and damage profile ahead of the cave.

While the two studies listed here are not particularly representative of modern block caving operations, some knowledge can still be extracted from them. The observation of what appears to be fracture banding give further indications that the importance of this phenomenon in cave evolution has not been recognized to date.
Although these studies indicate that fracture banding is reproducible by different researchers using different materials and different testing methods (centrifuge and friction table), this cannot be used on its own to support the idea that the phenomenon would also occur in real cave mines, nor does it give any indication of its importance in the caving process in a real cave. For this reason, studies that include field observations are essential.

\section{Observations at caving mines}

A number of authors have noted tensile fractures in both the crown and the periphery of block caves and open stopes that have caved (Heslop, 1976; Panek, 1981; Lorig et al., 1989; Sharrock et al., 2002; Carlson and Golden, 2008). These tensile fractures were found using direct visual observations, extensometers, time domain reflectometry (TDR) cables, and borehole camera observations.

Heslop (1976) found horizontal tensile fractures developing above the cave back through visual observations of old cut-and-fill workings above the cave back, which were also inferred through extensometer measurement. He made important strides in defining stress and subsidence caving; however, he did not create a conceptual model for the damage ahead of the cave back. The direct observations of tensile fractures are significant in that they reveal the importance of this failure mechanism in the caving process.

Using TDR monitoring, Carlson and Golden (2008) identified multiple instances of potential tension cracks parallel to the cave advance in the periphery of the Henderson 7210 cave.

Using in-hole camera surveys, Sharrock et al. (2002) observed two types of rock mass failure above an open stope that had caved at the Mt Isa Mines lead mine. The first was large, widely spaced extensional fractures at a distance from the stope crown and parallel to the excavation surface. The second was a composite failure between discontinuities and intact rock observed within $10 \mathrm{~m}$ of the crown.

Lorig et al. (1989) investigated caving of an open stope at Falconbridge East mine. They noted that core discing in boreholes above the stope back supported the idea that high stress caused shear and tensile failure.

Several of these authors found that the tensile fractures manifested as a series of discontinuities parallel to the cave front (Panek, 1981; Sharrock et al., 2002; Carlson and Golden, 2008). It appears that these may be observations of fracture banding.

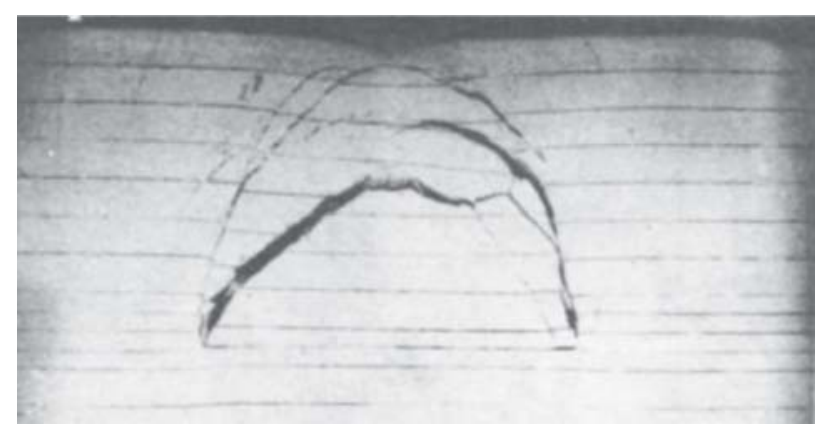

Figure 9-Typical cave-in test (Nishida et al., 1986) 


\section{Fracture banding in caving mines}

Of these studies, only Panek (1981) included an in-depth discussion of the importance of the parallel extensile fractures he observed in the caving process. The results of Panek's monitoring programme at San Manuel mine suggested a series of parallel extension fractures with strike angles tangential to the cave boundary, forming a 'roughly circular fractured zone of expansion about each active cave'. This concept is illustrated in Figure 10.

Panek stated that, in theory, the same extensional fractures tangential to the cave boundary should occur above and below the caved block. However, no measurements were made directly above the cave. Panek also postulated that this fracturing pattern can influence the potential for the rock mass to cave upward toward the surface, which would have a significant impact on the viability of caving projects. No further studies were conducted to verify if the fracturing extended above and below the active cave, nor were any efforts made to determine why the failure manifested as a series of parallel fractures. Panek's interpretation was based on direct observations, making it an important contribution, which seems to have been lost in the modern understanding of cave mechanics.

\section{Studies using numerical modelling}

While there is an abundance of literature dealing with numerical modelling of block caving, the existing literature tends to interpret results within the Duplancic model of caving and often focuses on the ability of numerical models to predict the cave geometry or subsidence profile. There is limited literature that attempts to better understand caving mechanics and the fracture pattern ahead of the cave using numerical models.

A notable exception is the work of Garza Cruz and Pierce (2014), who investigated the failure mechanisms in the crown of cave mines. They modelled a cube with sides of $8 \mathrm{~m}$, with a material model simulating a massive, veined rock mass. Loading conditions analogous to those in a cave back were introduced. Significant maximum and intermediate principal stresses (horizontal) were applied while the minimum principal stress (vertical) was unloaded in increments at the bottom of the cube while being maintained at the top of the cube.

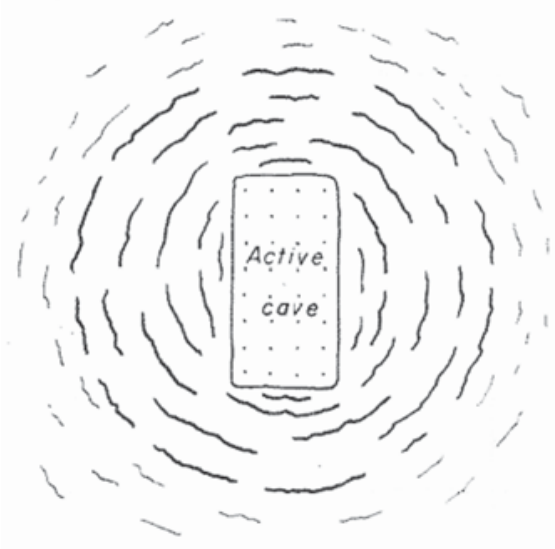

Figure 10-Parallel fractures in a circular zone around an active cave (after Panek, 1981)
The authors found that as the vertical stresses at the cave back decrease, high differential stresses induce shear failure and tensile fractures develop simultaneously sub-parallel to the face. These tensile fractures sub-parallel to the caving face could be interpreted as fracture banding. It was noted that the cave back showed progressive spalling as the back failed and stress was shed upwards. No further details were given on the importance of the tensile fractures during the cave progression.

There are several other studies, focusing on areas other than cave mechanics, that contain illustrations showing discontinuous damage ahead of the cave back, often in the form of a series of fractures parallel to the cave back (Vyazmensky i., 2007; Lisjak et al., 2012; Li et al., 2014). All of these examples use combined continuum-discontinuum (finite-discrete element method) codes. An example of this can be seen in Figure 11. These cases give yet another indication that fracture banding may be an important mechanism in cave development, but that its significance has not been recognized.

The study by Li et al. (2014) was the only one of these studies to look at the damage profile ahead of the propagating cave in some detail. The authors describe the failure ahead of the cave as a series of pressure-balancing arches and stress-release zones. It was postulated that in order for the cave to grow, the pressure-balancing arches must be broken, either by extension of the undercut or by further drawing of caved material. The failure in the model was primarily intact rock failure between existing joints that formed the pressure-balancing arches. While this numerical model shows some evidence for it, the authors do not specifically address the discontinuity of the damage, nor do they try to relate the phenomenon to any field data.

It appears that fracture banding propagation occurs only in contimuum-discontinuum hybrid models where the fracturing precess is explicitly modelled. We could not find

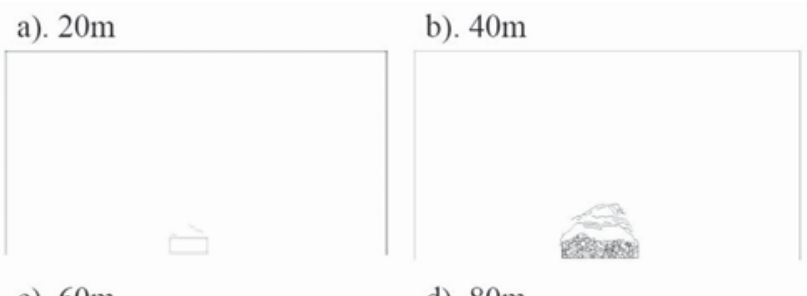

c). $60 \mathrm{~m}$

d). $80 \mathrm{~m}$

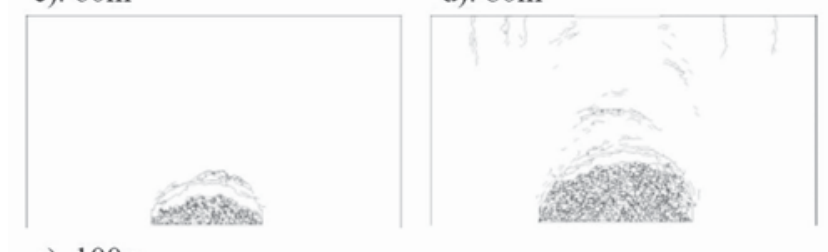

e). $100 \mathrm{~m}$

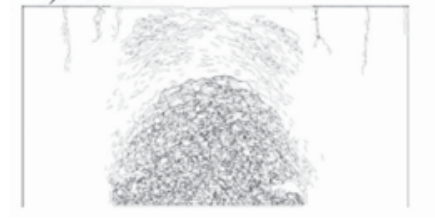

Figure 11-Cave growth for different undercut widths using an equivalent continuum approach (Vyazmensky et al., 2007) 


\section{Fracture banding in caving mines}

any example in the literature where a fracture banding phenomenon was modelled using a purely continuum modelling approach, without any explicit modelling of fracturing.

\section{Analysis of microseismicity}

Since the Duplancic (2001) publication, microseismic monitoring has become commonplace in caving mines. A study was performed to look for evidence from microseismic monitoring that could support the notion of fracture banding occurring in real cave operations.

For this purpose, analysis of microseismicity at two larger copper-gold porphyry block cave operations was undertaken. The analysis revealed indications that fracture banding was taking place as part of cave evolution. There were many instances where 'bands' of high microseismic event density alternated with 'bands' of low microseismic event density. This can be seen in Figure 12 to Figure 14, with the bands being highlighted in Figure 12B to Figure 14B. The microseismic events are coloured according to the date on which they occurred.

This pattern of microseismicity is not always observable at all times and in all locations in the crown and periphery of both mines. There are several possible explanations for this. The first is that conditions necessary for fracture banding to occur are not always met and that, at times, the cave propagates via another failure mechanism. It is also possible that the spacing of the fractures is closer to, or in the same order of magnitude as, the general location accuracy of the system. Another possible explanation is that the parallel extensional fractures form a beam, which subsequently begins to fail, creating microseismic events throughout the spatial volume.

Based on consultation with site personnel, there is no reason to believe that the bands of microseismicity are related to geology or were caused by any artefact of the seismic system. This is most likely due to the caving process created by the upwards expansion of the cave.

These examples of bands of microseismicity imply that fracture banding may be present at both Mine A and Mine B and, in turn, that it may be an important mechanism in cave propagation in general. The authors have also found indications in the microseismic records of other mines that bands of microseismicity may be forming.

\section{Conclusions}

Multiple sources indicate that fracture banding is an important mechanism in cave evolution. Physical models of caving tested in a geotechnical centrifuge suggested that the primary mechanism for cave evolution is through a series of fractures parallel to and ahead of the cave back, creating a clearly discontinuous damage profile.

In the literature there are examples from observations, instrumentation, and numerical models that indicate extensile fracturing and discontinuous damage ahead of the cave back. This suggests that the phenomenon observed in the laboratory is present in the field, although its significance may not have been appreciated by the individual observers.

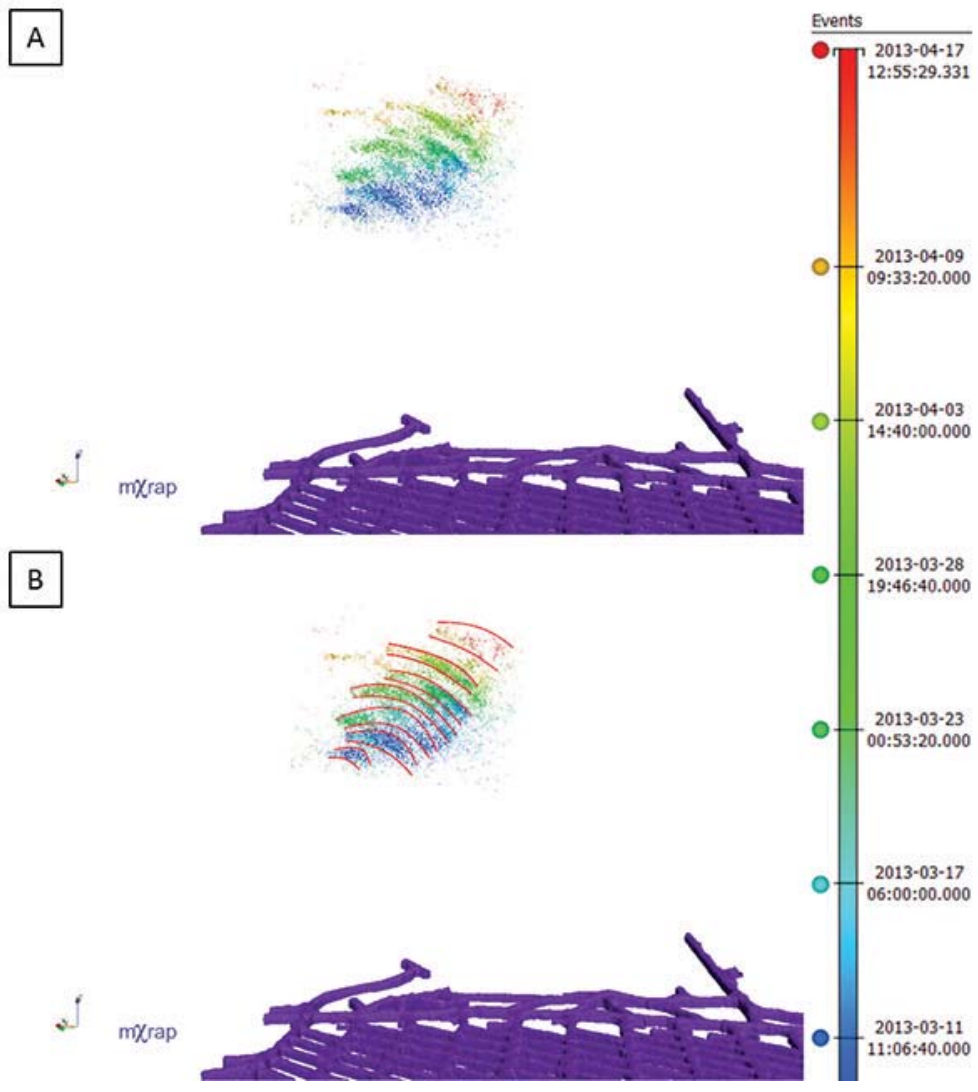

Figure 12-First example of bands of microseismicity at Mine A, with the production level shown in purple 


\section{Fracture banding in caving mines}

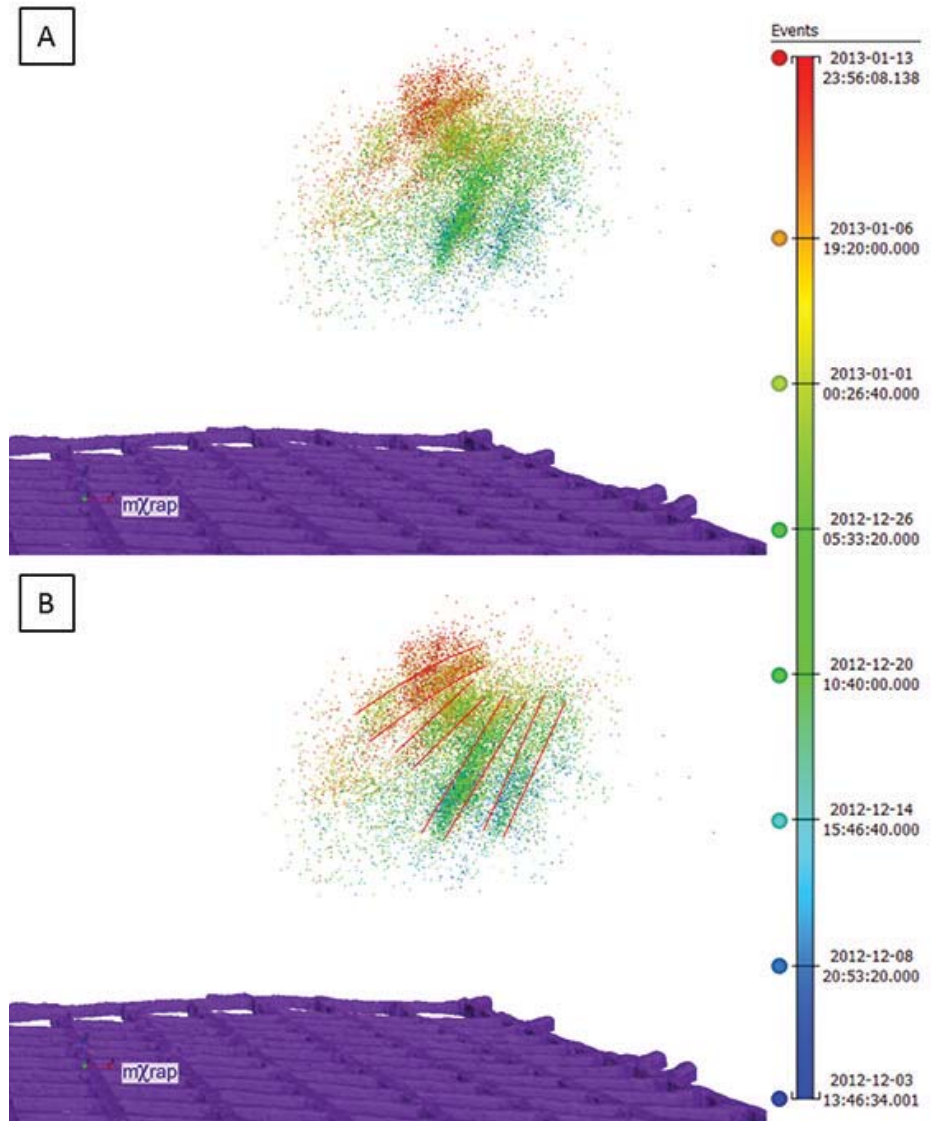

Figure 13-Second example of bands of microseismicity at Mine A, with the production level shown in purple

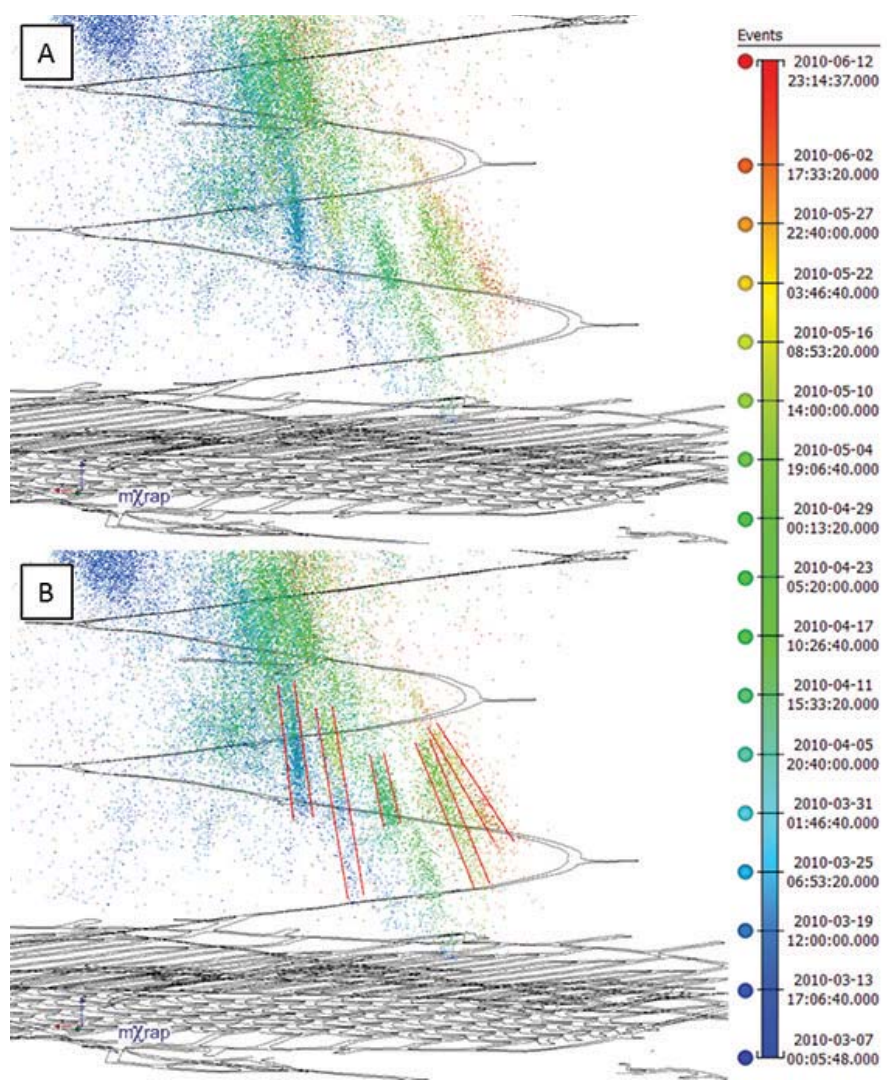

Figure 14-Example of bands of microseismicity at Mine B, with development shown as black lines 


\section{Fracture banding in caving mines}

Analysis of microseismicity also revealed that in some circumstances, repeated bands of microseismicity alternating with low or no microseismicity occur that may be interpreted to represent fracture banding.

Considering the evidence from physical models, direct field observation, and microseismic monitoring, it appears that fracture banding is a mechanism that contributes to cave propagation. The Duplancic model of caving, which is commonly interpreted as implying a continuous damage profile and downplaying the role of extensional failure, is not applicable in all cases and needs to be extended.

Access to the cave back and direct observation of the caving process is limited and the phenomenon of fracture banding is difficult to observe. These facts, in combination with the important role that fracture banding plays in caving propagation in the physical models, make it reasonable to expect that this process may play a much larger role in the field than has previously been recognized.

Further research needs to be conducted in order to determine the conditions under which fracture banding occurs and its significance with respect to cave design and management.

\section{References}

Abolfazlzadeh, Y. 2013. Application of seismic monitoring in caving mines case study of Telfer Gold Mine. MSc thesis, Laurentian University.

Brown, E.T. 2007. Block Caving Geomechanics. 2nd edn. Julius Kruttschnitt Mineral Research Centre, University of Queensland.

CARLSON, G. and Golden, R. 2008. Initiation, growth, monitoring and management of the 7210 cave at Henderson Mine - a case study. Proceedings of the 5th International Conference and Exhibition on Mass Mining (MassMin 2008), Luleå, Sweden, 9-11 June 2008. Schunnesson, H. and Nordlund, E. (eds.). Luleå University of Technology. pp. 97-106.

Cumming-Potvin, D., Wesseloo, J., Jacobsz, S.W., and Kearsley, E.P. 2016. Results from physical models of block caving. Proceedings of the 7 th International Conference and Exhibition on Mass Mining (MassMin 2016), Sydney, Australia, 9-11 May 2016. Australasian Institute of Mining and Metallurgy, Melbourne. pp. 329-340.

DuPLANCIC, P. 2001. Characterisation of caving mechanisms through analysis of stress and seismicity. PhD thesis, University of Western Australia.

Duplancic, P. and BRADY, B.H. 1999. Characterisation of caving mechanisms by analysis of seismicity and rock stress. Proceedings of the 9th ISRM Congress, Paris, France, 25-28 August 1999. International Society for Rock Mechanics. pp. 1049-1053.

Garza Cruz, T.V. and Pierce, M. 2014. A 3DEC model for heavily veined massive rock masses. Proceedings of the 48th US Rock Mechanics/Geomechanics Symposium, Minneapolis, 1-4 June 2014. American Rock Mechanics Association.

HeSLOP, T.G. 1976. Rock mechanics aspects of block caving chrysotile asbestos orebodies at Shabanie mine, Rhodesia. MSc thesis, University of the Witwatersrand.

Hudyma, M. and Potvin, Y. 2008. Characterizing caving induced seismicity at Ridgeway gold mine. Proceedings of the 5th International Conference and Exhibition on Mass Mining (MassMin 2008), Luleå, Sweden, 9-11 June 2008. Schunnesson, H. and Nordlund, E. (eds.). Luleå University of Technology. pp. 931-942.
Jacobsz, S.W., KeARSLEy, E.P., and Kock, J.H.L. 2014. The geotechnical centrifuge facility at the University of Pretoria. Proceedings of the 8th International Conference on Physical Modelling in Geotechnics, Perth, Australia. Gaudin, C. and White, D. J. (eds.). Taylor and Francis, Boca Raton, FL. pp. 169-174.

LI, L.C., TANG, C.A., ZHAo, X.D., and CAI, M. 2014. Block caving-induced strata movement and associated surface subsidence: a numerical study based on a demonstration model. Bulletin of Engineering Geology and the Environment, vol. 73, no. 4. pp. 1165-1182.

LisjaK, A., Tatone, B., Mahabadi, O., and Grasselli, G. 2012. Block caving modelling using the Y-Geo hybrid finite-discrete element code. Proceedings of the 6th International Conference and Exhibition on Mass Mining (MassMin 2012), Sudbury, 10-14 June 2012. CIM, Montreal.

LORIG, L.J., HART, R.D., BOARD, M.P., and SwAN, G. 1989. Influence of discontinuity orientations and strength on cavability in a confined environment. Proceedings of the 30th US Symposium on Rock Mechanics (USRMS), Morgantown, West Virginia, 19-22 June 1989. Balkema. pp. 167-174.

McNEARNy, R.L. and ABEL, J.F. 1993. Large-scale two-dimensional block caving model tests. International Journal of Rock Mechanics and Mining Sciences, vol. 30, no. 2. pp. 93-109.

NishidA, T., EsAKI, T., and KAMEDA, N. 1986. Development of the base friction technique and its application to subsidence engineering. Proceedings of the International Symposium on Engineering in Complex Rock Formations, Beijing, China, 3-7 November 1986. LI, C. and Yang, L. (eds.). Science Press. pp. 386-392.

PANEK, L.A. 1981. Ground movements near a caving stope. Design and Operation of Caving and Sublevel Stoping Mines. Stewart, D. (ed.). Society of Mining Engineers of AIME. New York, USA. pp. 329-354.

Pfitzner, M., Westman, E., Morgan, M., Finn, D., and Beck, D. 2010. Estimation of rock mass changes induced by hydraulic fracturing and cave mining by double difference passive tomography. Proceedings of the 2nd International Symposium on Block and Sublevel Caving. Potvin, Y. (ed.). Australian Centre for Geomechanics, Perth. pp. 677-684.

Sharrock, G., Slade, N., Thin, I., and Duplancic, P. 2002. The prediction of stress induced caving on a mining abutment. Proceedings of the 1st International Seminar on Deep and High Stress Mining, Perth, Australia, 6-8 November 2002. Potvin, Y., Hadjigeorgiou, J., and Stacey, T. (eds.). Australian Centre for Geomechanics, Perth.

STACEY, T.R. 1981. A simple extension strain criterion for fracture of brittle rock. International Journal of Rock Mechanics and Mining Sciences \& Geomechanics Abstracts, vol. 18, no. 6. pp. 469-474.

Vyazmensky, A., Elmo, D., Stead, D., and Rance, J.R. 2007. Combined finitediscrete element modelling of surface subsidence associated with block caving mining. Rock Mechanics: Meeting Society's Challenges and Demands. Eberhardt, E., Stead, D., and Morrison, T. (eds.). Taylor and Francis, Boca Raton, FL. pp. 467-476.

Westman, E., LuXbacher, K., and Schafrik, S. 2012. Passive seismic tomography for three-dimensional time-lapse imaging of mining-induced rock mass changes. The Leading Edge, vol. 31, no. 3. pp. 338-345. 